\title{
CUSTOMER ATTITUDES TOWARDS RESTAURANT RESERVATIONS POLICIES
}

\author{
Sheryl E. Kimes \\ School of Hotel Administration \\ Cornell University \\ Ithaca, NY, USA \\ sek6@cornell.edu
}

\begin{abstract}
Reservations give restaurants the capability to select the most profitable mix of customers and help them better control their time. Reservations are not without problems because of the uncertainty associated with customers honoring their reservation and with the uncertainty associated with the length of time that customers will use the service. Many restaurants have developed policies to handle these uncertainties; the question is how customers react to such policies. An online survey on customer attitudes towards restaurant reservation policies was conducted in the United States. Respondents considered table-holding policies and credit card guarantees to be the most acceptable and fairest of the five policies considered. Entire party seating policies were viewed in a mostly neutral manner, while respondents had a mixed view of maximum duration policies. Short-show policies were considered to be the least understandable and acceptable. In all cases, customers who were more familiar with a policy were more likely to consider that policy to be acceptable and fair.
\end{abstract}

Keywords: revenue management; restaurants; duration control; customer satisfaction 


\section{INTRODUCTION}

Restaurants and other capacity-constrained service firms that practice revenue management (RM) often use reservations and appointments to help select the most profitable mix of customers. Customer demand varies, and reservations and appointments give companies control over when customers arrive and how long they stay. Reservations and appointments are not without problems because of the uncertainty associated with customers honoring their reservation or appointment and with the uncertainty associated with the length of time that customers will use the service.

Restaurants, like companies in other industries that use RM have three strategic levers that they can use to help maximize revenue: price, time and space (Kimes and Chase, 1998). Price can be manipulated by charging different prices at different times and to different market segments, whereas space can be managed by ensuring the company has an appropriate supply mix. Time can be used by controlling the timing and flow of customer arrivals or by regulating the time of customer usage.

Methods of managing space and time are fairly consistent across industries, but managing time is much easier in industries that explicitly sell time (that is, a night at a hotel, an hour at a spa or a performance at a theatre) than for companies that implicitly sell time (that is, a restaurant meal or a round of golf). Industries that sell time implicitly can typically not ask customers how long they need to use the firm's capacity. Without this information, managing time becomes much more difficult.

When managing time, restaurants can use both internal (not involving customers) and external (involving customers) measures (Kimes et al, 1998). Implicit measures include forecasting the number and timing of customer arrivals, streamlining the service delivery process to increase the predictability of the length of the meal and developing a reservations system that effectively regulates customer flow. Examples of external include ensuring that customers honor their reservation by imposing a credit card 
guarantee (similar to hotels and airlines), trying to make sure customers arrive on time (by not holding the table for more than a certain length of time) or imposing a maximum dining duration limit on customers.

In high demand periods, certain external controls become appealing. For example, if a restaurant can reduce the no-show rate, have customers show up on time with the right number of people in their party and stay for an agreed upon time, restaurant utilization and profitability could increase. The question is how restaurant customers would react to external control policies. External time management tools are the subject of this research.

I will first discuss some of the issues associated with reservations, give a brief review of the relevant research and then present the results of a nationwide online customer survey on restaurant reservations policies that was conducted in the United States in the fall of 2008. I will conclude with a discussion of the implications of the findings for researchers and practitioners.

\section{RESTAURANT RESERVATIONS}

Reservations not only give restaurants the opportunity to select the most profitable mix of customers but also help them better schedule their staff and workflow (Fischer, 2005). Reservations give customers an assurance that capacity has been set aside for them and give customers more control over their time (Kimes and Wirtz, 2007).

In an ideal world, customers would show up exactly on time and service times would be completely predictable; unfortunately, not all customers honor their reservations, some show up late or early and service times are not always predictable. These problems have caused many casual restaurants to eschew reservations, but about a third of the largest US casual restaurant chains have take reservations 
because customers prefer to have them (Kimes and Wirtz, 2007). The question is one of how restaurants can obtain the advantages of reservations while managing the potential problems.

Research on restaurant reservations is fairly limited. Two articles have been published on optimal reservation policies (Bertsimas and Shioda, 2003; Thompson and Kwortnik, 2008) and two reports have been published on customer attitudes towards restaurant reservations and reservations policies (Kimes and Wirtz, 2007; Kimes, 2008). The latter stream of research is more relevant to this study.

Kimes and Wirtz (2007) studied restaurant-seating policies in casual restaurants and found that respondents preferred reservations to waitlist seating and call-ahead seating (customers can call ahead and have their name placed on a waitlist). Respondents felt that reservations gave them additional control and were more convenient than the other seating policies. In addition, they believed that restaurants that offered reservations had a stronger customer focus than those that did not take reservations.

Kimes (2008) conducted a voluntary response survey of customer reaction to seven different restaurant reservations policies (credit card guarantee, short-show penalties, table-holding, entire party seating, minimum party size, maximum duration and premium pricing) and found that respondents considered credit card guarantees and table-holding policies to be the fairest. Maximum duration, premium pricing and minimum party size were considered to be the least fair. Although the findings of the study are interesting, they are limited by the nature of the sample.

Restaurants that take reservations face four different time management issues: (1) no-shows: will customers arrive? (2) Late shows: will customers arrive at the specified time? (3) short-shows: will customers show up with the number of guests specified in the reservation? and (4) dining duration: how long will customers stay? Methods for managing each of these and the potential customer satisfaction issues associated with each will be discussed below. 
1. No-shows: Restaurants have several approaches for ensuring that customers honor their reservation. They can call and remind customers of their reservation or require that customers call or e-mail the restaurant to reconfirm their reservation. More aggressive methods are also available. Restaurants can require a credit card guarantee and charge either a full or partial penalty per person if the party does not show up; they can require either a deposit or full payment in advance; or they can charge a penalty if the reservation is not cancelled within a certain time period (often 24-48 hours).

A number of industries (including the hotel and airline industry) use credit card guarantees and have found that such a guarantee reduces the no-show rate since customers are forced to become more responsible for showing up or face a financial penalty. Similar results have been found in the restaurant industry.

While credit card guarantees may be attractive, restaurant operators need to consider the impact on customer satisfaction, the ease with which customers can contact the restaurant to cancel or change their reservation and procedures for managing situations which may prevent customers from cancelling their reservation.

2. On-time arrival : When customers are late for their reservation, the restaurant may be forced to turn away other guests and may lose money because of the unused table. To alleviate this problem, many restaurants only hold the table for a specified length of time before seating the next party at that table. When the late party arrives, they are either given the next available table or are put back into the queue of parties waiting for a table. This policy is also beneficial to other customers who might have to wait longer because of the late arriving party.

In addition, many restaurants require that the entire party be present before the party is seated. Complete party seating makes sense from an operational perspective because restaurants generally have to be reconfigured for larger parties. If the complete party either does not show up 
or shows up over time it may require later-arriving parties to wait for their tables.

Like other reservations policies, this can have two types of effects on satisfaction. Customers who must wait for others in their party before being seated may resent having to wait. In addition, other parties who are forced to wait because of this may resent waiting because their table wasn't ready when promised.

3. Right number in the party: When customers make a reservation, they specify the number of people in their party. The restaurant then uses this information to assign the appropriate table and to make staffing and purchasing decisions. If the party shows up with fewer customers than expected, the restaurant faces two potential costs: (1) the opportunity cost of the empty seat and (2) overstaffing and purchasing costs incurred because of the expected additional customers. Obviously, one less customer will not have a significant impact on costs, but if this occurs over multiple parties over an evening, it can have a substantial effect on profitability. While a charge for short-shows makes sense from an operational perspective, customers may feel as if they do not have control over their party size and may have difficulty in notifying the restaurant of any changes in that number.

4. Meal duration: As restaurants do not explicitly sell time, it becomes difficult to manage capacity during busy periods because of the uncertainty associated with meal duration. Restaurants can reduce this uncertainty by imposing a reasonable time limit on meals. Reasonable means sufficient time for customers to enjoy their experience and long enough for the restaurant to be able to deliver a consistent and quality experience (Bauer, 2006). This allows restaurants to better plan their reservations and helps assure customers that their table will be ready when they arrive. 
While this makes sense from the restaurant's perspective and from the later-arriving customer perspective (Bruni, 2006), it may not be acceptable to customers who are subject to the time limit since they may feel as if they are being rushed and not being allowed to enjoy the full experience (Noone and Kimes, 2005; Noone et al , 2007).

Restaurants that take reservations need to gain additional control over customer arrival and meal duration behavior so that they can effectively use RM. Without this control, they only have two of the three strategic levers (space and price) with which to manage their revenue. While customers prefer to have a reservation, they may be uncomfortable with some of the external measures that restaurants might use to better control customer arrival and duration. The purpose of this research was to determine how customers evaluate the fairness of various restaurant reservation policies.

\section{LITERATURE REVIEW}

Five streams of research seem to relate directly to the impact of restaurant reservation policies on customer satisfaction: (1) perceived fairness, (2) service delays, (3) perceived control, (4) convenience and (5) familiarity.

\section{Perceived fairness}

Perceived fairness is defined as whether consumers consider the outcome and transaction process to be reasonable, acceptable and just (Bolton et al, 2003). Perceived fairness has been studied in a variety of industries (Thaler, 1985; Kahneman et al, 1986; Urbany et al, 1989; Kimes, 1994; Campbell, 1999a, 1999b; Kimes and Wirtz, 2003; Wirtz and Kimes, 2007) and has been found to be a key factor to maintaining customer satisfaction, loyalty and long-term profitability. 
All fairness perceptions are comparative in nature (Xia et al, 2004). Two conceptual comparative frameworks widely used to explain fairness perceptions are the principle of dual entitlement, and the concepts of reference price and reference transaction.

The principle of dual entitlement states that most customers believe that they are entitled to a reasonable price and the firm is entitled to a reasonable profit (Kahneman et al, 1986). In the case of reservations, price may be viewed as an intangible cost for the consumer (whether in the form of waiting

or inconvenience). The principle of dual entitlement with restaurant reservations is that customers believe that they are entitled to reasonable treatment and that the firm is entitled to a reasonable profit.

In addition to dual entitlement comparisons, consumers' perceived fairness may be based on comparative or highly similar transactions (Xia et al, 2004) or reference transactions (Kimes and Wirtz, 2003). To assess the fairness of a transaction, customers often rely on the last transaction experienced, the most frequent type of transaction, as well as accepted industry practice (Kahneman et al, 1986).

\section{Service delays}

Research has shown a negative relationship between perceived waiting time and customer satisfaction. Customers tend to overestimate wait times (Katz et al, 1991; Tom and Lucey, 1997; Pruyn and Smidts, 1998) and research indicates that the perceived length of the wait has more impact on satisfaction than does the actual waiting time (Katz et al, 1991; Davis and Heineke, 1998; Pruyn and Smidts, 1998). Anything that can be done to reduce the perceived waiting time should result in an increase in customer satisfaction and preference.

Satisfaction is particularly affected by having to wait during the pre-process part of the service (Dube-Rioux et al, 1988). For example, in a restaurant setting, the pre-process wait is defined from when customers arrive at a restaurant until they are seated and receive their first food item. Similarly, in an 
airline context, the pre-process wait is from when customers arrive at the airport until their plane takes off.

Pre-process waits have been divided into three types: (1) pre-schedule waits (when a customer arrives early for a reservation), (2) delays (when someone shows up on time for a reservation but must wait) and (3) queue waits (when reservations are not taken) (Taylor, 1994).

Delay waits are particularly relevant to reservations because customers may not be served at the designated time. Customers who experience delay waits are likely to be frustrated, particularly if they view the company as responsible for the delay. Taylor (1994) in her study of delay waits in airlines found that service delays negatively affect the evaluation of a service. The evaluations were affected by the degree to which the customers felt that the company had control over the delay and how the company helped ease customer's feelings of uncertainty and anger.

Companies often have difficulty in controlling delay waits because of the time unpredictability associated with previous customers, customers who arrive early or late for their reservation, no-shows and unpredictable events (such as traffic congestion).

In order to control delay waits, restaurants must control service duration without rushing customers. In addition, they should discourage late arrivals, overbook or charge for no-shows, include slack for unpredictable events, and make it easy for customers to contact the restaurant if they are running late or cannot make it.

\section{Perceived control}


Research on perceived control (Averill, 1973; Langer, 1983; Hui and Bateson, 1991; Hui and Tse, 1996) has shown that when customers perceive that they have more control over a service encounter, they are more likely to be satisfied with that encounter.

Perceived control has a positive impact on customer well being and on service satisfaction. For example, Langer and Rodin (1976) found in their study of nursing homes that when nursing home residents were given additional control over when they ate or when visiting hours were scheduled, they were happier, more active and lived longer. Langer and Saegert (1977) found a similar relationship between perceived control and customer satisfaction.

Three types of perceived control have been proposed: behavioral, cognitive and decisional (Averill, 1973). Customers have behavioral control when they can directly influence or modify what happens to them (Hui and Bateson, 1991). In a reservations context, customers can exert behavioral control by choosing the time of their reservation, by letting the company know that they will be unable to honor their reservation or by letting the company know that they are running late. They can also exert behavioral control by regulating the pace of the meal (Noone et al, 2007).

Cognitive control is related to the predictability and interpretability of a situation. Research has shown that additional information leads to a more positive evaluation of the service. In a restaurant context, if customers know how long they have to wait before they are seated or seen, they will have increased cognitive control. Restaurants can also set expectations of cognitive control by telling customers the length of the meal experience.

Finally, decisional control concerns the control that a customer has over the selection of outcomes and goals. For example, in a restaurant seating context, customers lose decisional control when a restaurant does not seat them until all of their party has arrived or if they penalize the customer for having fewer people in the party than specified in the reservation. 


\section{Service convenience}

Service convenience is related to customer desire to conserve time and effort. Five types of service convenience have been proposed: (1) decision convenience, (2) access convenience, (3) transaction convenience, (4) benefit convenience and (5) post-benefit convenience (Berry et al, 2002). An increase in service convenience has been theorized to be associated with an increase in satisfaction (Berry et al, 2002). The most relevant types of convenience in a restaurant reservation setting are transaction and benefit convenience.

Decision convenience concerns the time and effort required to make a service purchase or use decisions. For example, when customers select a restaurant they use many sources of information to make that decision. Restaurant reviews and online ratings increase decision convenience by making it easier for customers to make a decision.

Access convenience is related to the time and effort needed to order or purchase a service. If a restaurant can separate receiving the service from requesting the service, they can increase access convenience. For example, customers can either call a restaurant to make a reservation or use an online service such as Opentable.com or Dinnerbroker.com to make their reservations.

Transaction convenience is related to the perceived time and effort needed to secure the right to use a service. When customers have to put time and effort into waiting before they experience a service, satisfaction is likely to decrease. Anything that can be done to reduce this delay, whether through timely seating, duration controls on previous parties or improvements in service delivery systems should lead to increased transaction convenience. 
Benefit convenience is the perceived time and effort put in to experience the core benefit of the service. In a restaurant context, benefit convenience is associated with the actual dining experience. Customers do not normally want to minimize their time in this part of the meal and in fact prefer to linger. Efforts to speed up the core part of the dining experience are likely to lead to lower satisfaction (Noone and Kimes, 2005; Noone et al, 2007).

Post-benefit convenience is determined by the time and effort needed to reinitiate contact with the firm after the benefit has been received. An example in a restaurant context would be contacting the restaurant after the meal to enquire about the opening times or a lost pair of glasses.

\section{Familiarity}

Customers are affected by community norms of reference transactions, and customers' perceptions of fairness are judged relative to these community norms (Kahneman et al, 1986). In an RM context, there is also evidence that customers are shifting their fairness perceptions to community norms (Kimes, 1994; Kimes and Noone, 2002). This suggests that as a market becomes more familiar with RM practices, the unfairness perceptions of those practices decline over time (Wirtz and Kimes, 2007). Customers who are familiar with an RM practice are likely to have already adjusted their reference transaction and reference price with less, or even no impact on perceived fairness.

Familiarity has been shown to directly affect the perceived fairness of RM practices. In the context of this study, I propose that respondents who are more familiar with a reservation policy will consider that policy to be more acceptable, understandable and fair than those who are less familiar with a policy.

\section{THE STUDY}


A nationwide online customer survey was conducted in the United States in the fall of 2008. The survey included questions on expectations of and reasons for reservations as well as questions on seven different reservations policies. Respondents were also asked to provide reasons as to why they answered the way they did. Several demographic questions were also included. The overall results from the customer survey will be presented first followed by a discussion of the survey results for each specific reservations policy.

About half of the 816 respondents (51.6 per cent of the respondents) were female. About a quarter (26.5 per cent) were between 25 and 39 years old with 11.1 per cent under 25, 29.6 per cent between 40 and 54 and 32.8 per cent were 55 or over.

About a quarter of the respondents (25.2 per cent) went out for dinner at restaurants that take reservations at least once per month while another 52.1 per cent went out to this type of restaurant several times a year. Nearly a quarter (22.8 per cent) did not go to this type of restaurant at all.

Respondents evaluated five different reservations policies (credit card guarantees, late show, short-show, entire party seating and maximum duration limits). For each reservations policy, we asked respondents to evaluate the acceptability (1=Extremely Unacceptable, 7=Extremely Acceptable), understandability (1=Not at all Understandable, 7=Highly Understandable), unfairness (1=Extremely Fair, 7=Extremely Unfair) and to indicate their familiarity (1=Extremely Unfamiliar, 7=Extremely Familiar) with the policy. For each statement, an average rating above 5.5 was considered to indicate strong agreement; between 4.5 and 5.49, simple agreement; 3.5 to 4.49, neutral; 2.5-3.49, disagreement; and below 2.5, strong disagreement.

I did not explicitly ask questions on perceived control and access convenience, but instead measured them through the qualitative comments that the respondents provided (about 70 per cent provided feedback). Three independent observers classified the comments into multiple categories. The 
categories were then compared, refinements were made and the observers reclassified the comments based on the revised categories. The classifications were checked for agreement and after some minor adjustments were finalized. The qualitative data allowed for additional insight into the drivers of respondent attitudes. With a few minor exceptions, the qualitative categories for each reservation policy did not vary by age, gender or frequency of dining out.

The specific results for each of the reservations policies will be discussed first followed by a comparison of the results across reservations policies.

\section{Credit card guarantees}

Respondents were neither familiar nor unfamiliar with credit card guarantees (3.67). They viewed them as understandable (4.62) and were neutral on their acceptability (4.27). Credit card guarantees were considered to be a fair practice (3.30). Customers who were more familiar with credit card guarantees viewed them as significantly more understandable, acceptable and fair. There were slight differences by reservation usage and age. Respondents who made reservations more frequently were more familiar with credit card guarantees. Younger respondents felt that credit card guarantees were significantly less fair than older respondents.

Nearly three-quarters (74.5 per cent) of the respondents provided qualitative feedback on credit card guarantees. These qualitative comments were broken into eight categories. The majority of the comments were favorable. The most common comments were 'restaurants are in business and need to protect themselves against no-shows', 'this is a fair policy' and 'this is an unfair policy'. The categories, their descriptions and the percentage for each category are given in Table 1.

\section{[TABLE 1]}




\section{Short-shows}

Respondents were unfamiliar with short-show penalties (2.58) and viewed this policy as difficult to understand (3.01) and unacceptable (2.82). Short-show policies were considered to have neutral fairness (4.30). Respondents who were more familiar with short-show penalties viewed them as significantly more understandable, more acceptable and fairer than those with less familiarity. There were slight differences by reservation frequency, age and gender. Respondents who made reservations more frequently and male respondents were more familiar with short-show policies and felt that they were more understandable and acceptable. Younger respondents felt that short-show policies were more acceptable than older respondents did.

Nearly 70 per cent (68.9 per cent) of the respondents provided qualitative feedback on short-show policies. Their qualitative comments were broken into seven categories. The most common comments were 'I don't have control over who in my party shows up', 'this policy is understandable' and 'this policy is unfair to the guest'. The categories, their descriptions and the percentage for each category are given in Table 2.

\section{[TABLE 2]}

\section{Entire party seating}

Respondents had a neutral view of the familiarity (4.31), acceptability (4.00), understandability (3.83) and fairness (3.58) of entire party seating policies. Those who were more familiar with entire party seating policies considered these policies to be significantly more acceptable, more understandable and fairer than those who were less familiar. Frequent reservation users were more familiar with entire party seating policies as were female respondents. Younger respondents were significantly more likely to view such policies as understandable and acceptable. 
Nearly 70 per cent (68.9 per cent) of the respondents provided qualitative feedback on entire party seating policies. Their qualitative comments were broken into eight categories. The most common comments were 'this policy is understandable', This policy is inhospitable' and 'I'm still spending if I'm seated when I arrive'. The categories, their descriptions and the percentage for each category are given in Table 3.

\section{[TABLE 3]}

\section{Table-holding policies}

Respondents were familiar with table-holding policies (4.69) and viewed them as understandable (5.32) and acceptable (5.25). Table-holding policies were considered to be the fairest of all of the reservations policies studied (2.69). Respondents who were more familiar with table-holding policies considered these policies to be significantly more acceptable, more understandable and fairer than those who were less familiar. Frequent reservation users were more familiar with table-holding policies and felt that they were more understandable and fairer. Female respondents felt that table-holding policies were significantly more acceptable than male respondents.

The qualitative comments reflected the positive attitudes customers had towards table-holding policies. The most common comments were 'customers should call the restaurant if they're running late' and 'this policy is fair'. The categories, their descriptions and the percentage for each category are given in Table 4.

\section{[TABLE 4]}

\section{Maximum duration policies}

Respondents were unfamiliar with maximum duration policies (3.09) and viewed such policies as unacceptable (3.24) and with neutral understandability (3.53). Respondents viewed maximum duration 
policies as neither fair nor unfair (4.04). Those who were more familiar with maximum duration policies considered these policies to be significantly more acceptable, understandable and fair than those who were less familiar. Respondents who made reservations more frequently were more familiar with maximum duration policies and found them to be significantly fairer than respondents who made reservations less often. Male respondents believed that maximum duration policies were significantly more acceptable than did female respondents. Younger respondents were more familiar with maximum duration policies and found them to be more acceptable than older respondents.

The qualitative comments on maximum duration policies were mixed. The most common comments were 'this policy is inhospitable', 'this policy is understandable because the restaurant is a business' and 'this policy is understandable if the time allowed is reasonable'. Representative comments are given in Table 5.

\section{[TABLE 5]}

\section{Overall results}

\section{Fairness}

Respondents were neutral about the fairness of maximum duration policies (4.04), short-show policies (4.30) and entire party seating (3.58). Table-holding policies (that is, holding the table for 15 min) were considered to be extremely fair (2.69) and credit card guarantee policies were considered to be relatively fair (3.30) (Figure 1).

Acceptability 
Respondents thought that table-holding policies were acceptable (5.25) and were neutral about credit card guarantee policies (4.27), entire party seating policies (3.83) and maximum duration policies (4.04). Respondents viewed short-show policies (2.82) as unacceptable (Figure 2).

\section{Understandability}

Respondents found short-show policies (3.01) to be not understandable. They were neutral on entire party seating policies (4.00) and maximum duration policies (3.53) but felt that credit card guarantees (4.62) and table-holding policies (5.32) were understandable (5.32) (Figure 3).

\section{Familiarity}

Respondents were neither familiar nor unfamiliar with three of the reservations policies (entire party seating, 4.31; credit card guarantees, 3.67; table-holding, 4.69). They were not familiar with maximum duration policies (3.09) and short-show policies (2.58) (Figure 4).

\section{Summary}

Table 6 summarizes the results for each of the five reservations policies. Table-holding policies and credit card guarantees were considered the most understandable, acceptable and fair. Entire party seating policies were viewed in a mostly neutral manner, while respondents had a mixed view of maximum duration policies. Short-show policies were considered to be the least understandable and acceptable.

\section{[TABLE 6]}

\section{DISCUSSION}

Respondents who were more familiar with a restaurant reservation policy found that policy to be significantly more acceptable, more understandable and fairer than those who were not as familiar. This 
result supports previous research on familiarity (Wirtz and Kimes, 2007) and suggests that restaurant operators should ensure that their customers are familiar with any policy that they decide to use to reduce the uncertainty associated with reservations.

The concept of control was frequently mentioned in the qualitative comments. Over a quarter (28.8 per cent) of the comments on the short-show policy mentioned the lack of control over whether their dining companions would show up and that it was unfair to be penalized for this. Representative comments included:

'Unexpected things happen. What if someone in the party is taken ill? Is it fair to charge the host for this?'

'You should not be held responsible if someone cancels at the last minute. Emergencies to come up'.

'The person making the reservation cannot control what the other people in the party does or doesn't do. Also I don't have options if I receive poor service or have to wait anyway for my table'.

This, combined with the fact that respondents viewed short-show policies to be unfair, suggest that restaurant operators approach the adoption of such a policy with great caution.

Lack of control was also mentioned for entire party seating (12.9 per cent) and credit card guarantees (8.7 per cent). The entire party seating comments were similar in nature to the short-show comments (that is, respondents felt that they did not have control over when their dining companions arrived and shouldn't be penalized for that). Representative comments included:

'It is O.K. but I would rather have the party seated as they arrive. Traffic can cause some members of the party to be delayed'. 
'I cannot control when other members of my party show up! In the meantime I'm kept waiting with other members of my party while people without reservations are being served'.

'Sometimes you don't know if all in your party is going to show up, therefore making everyone wait is stupid'.

The credit card comments generally revolved around the concept of not having control over unforeseen events that might cause them to not be able to make their reservation. Representative comments included:

'I think that if you make a reservation somewhere than it means you need to show up just like if you RSVP to a party. But I do think and understand that things do happen in life that might make those last min. changes (being a parent) But if you need to cancel for any reason then you should have a grace period to call and cancel. I think that would be fair. Because things do happen in life that are unexpected!'

'Few of us can plan for contingencies as far in advance as 24 hours. I think I'd rather eat someplace else'.

This suggests that operators who adopt entire party seating policies or decide to use credit card guarantees make it easy for customers to contact them to alert them to late arrivals or to cancel their reservation.

Access convenience was also a common topic among the qualitative comments. Over half (55.4 per cent) of the table-holding policy comments mentioned that customers could always call the restaurant to alert them to possible delays. Similar comments were made for the credit card guarantee (4.9 per cent) and short-show policies (3.6 per cent). These results suggest that restaurant operators should ensure that it is relatively easy for customers to contact them in case of a change in plans. Representative comments included: 
'The people that made the reservation could have got held up in traffic or were waiting for a baby sitter. But they should have called'.

'If you can't be courteous enough to at least call and let them know you'll be late, you don't deserve to keep the table. Everyone has a cell phone these days. How hard is it to call?'

'One should be on time or call if running late. That is the correct thing to do'.

Even though respondents who were familiar with maximum duration policies viewed such a policy as more acceptable, more understandable and more fair than those who were not familiar, over half (54.4 per cent) of the qualitative comments were negative and viewed the policy as extremely inhospitable. Representative comments included:

'How can you enjoy dinner with a big clock ticking over your head?'

'I make many business deals at dinner if they want to put a time limit on the table I will eat elsewhere'.

'I have only heard this about McDonald's, which is not a legal restaurant in Germany (those places are called Imbiss, NOT restaurant!). I cannot imagine this behavior for real restaurants. If this ever happened to us, I would pay the exact amount owed, no extra gift, the next day I would write an article about it on several blogs, like Yahoo local or Yelp etc. I would make this outrageous behavior public ad warn as many people as possible. Needless to say I would never again consider such a place'.

This implies that restaurant operators should exercise caution before adopting such an approach because of the potential negative effect on satisfaction. If more control is needed over customer duration, managers should consider either trying to streamline their service delivery process or using 'seatings' in which reservations have a specific starting and ending time. 


\section{CONCLUSIONS AND FUTURE RESEARCH}

Reservations give restaurants more control over customer time and can help them better use their capacity to generate revenue. Without this increased control, restaurants that practice RM would only be able to deploy two of the basic RM tools (space and price); this would be similar to a hotel or airline attempting to practice RM without knowing how long customers were going to use their capacity.

While reservations help restaurants select the most profitable mix of customers, restaurant operators must develop ways in which to manage the inherent uncertainty associated with customer arrival and meal duration. A variety of reservation policy options are available to reduce this uncertainty, but may have a negative impact on customer satisfaction. In this study, I found that customers who were familiar with a reservation policy considered that policy to be more acceptable, more understandable and fairer than those who were not familiar with the policy.

Respondents considered table-holding policies and credit card guarantees to be the most acceptable and fairest of the five policies considered. Entire party seating policies were viewed in a mostly neutral manner, while respondents had a mixed view of maximum duration policies. Short-show policies were considered to be the least understandable and acceptable.

The qualitative analysis indicated that perceived control and access convenience were considered to be important drivers of respondent attitude towards reservations policies. This implies that managers should ensure that they provide customers with ways to contact them to notify them of unforeseen problems and to not penalize their customers for things that they cannot control.

There were several limitations to the study. It was conducted in one country (United States) in a single industry. It would be useful to conduct it in additional countries and for additional industries, such 
as health care or professional services, that face the same sorts of reservation and appointment uncertainty issues as the restaurant industry. In addition, the survey was conducted online and it is possible that the attitudes of online respondents might be different than potential respondents who do not use the Internet.

In the future, it would be useful to study the drivers of fairness perceptions in more depth. The qualitative data provide a rich source which could be analyzed using more advanced text-mining approaches. Additional studies in which specific questions on perceived control and access convenience were included would also be useful and provide additional insight into the factors that drive customer perceptions of fairness.

Very little research has been conducted on restaurant forecasting, and forecasting models which could be applied to the restaurant reservations problem would be particularly helpful. Models that have been developed for other RM applications might prove useful, but would need to incorporate the stochastic nature of restaurant customer behavior. In addition, research on overbooking models for restaurant reservations would be quite useful.

Finally, research on optimal reservation methods would be extremely useful and interesting. Like airlines and hotels, restaurants would greatly benefit from algorithms that would help them determine the best number of reservations to take for different times and days that incorporate arrival and duration uncertainty issues.

Reservations give restaurants the opportunity to select the more profitable mix of customers. By understanding how to better manage customer time while maintaining customer satisfaction, restaurants can more effectively use their capacity to maximize revenue. 
Table 1. Credit card guarantee categories.

\begin{tabular}{|c|c|c|}
\hline Category & Description & Percentage \\
\hline Business & $\begin{array}{l}\text { The nature of the restaurant industry calls for securing reservations through } \\
\text { the use of a credit card guarantee. The restaurant is in business to make } \\
\text { money. It allows the manager to better plan for the evening. }\end{array}$ & 30.6 \\
\hline $\begin{array}{l}\text { Call and } \\
\text { cancel }\end{array}$ & $\begin{array}{l}\text { This policy still allows for the customer to call and cancel a reservation in } \\
\text { advance. If the customer does not cancel the reservation far enough in advance, } \\
\text { they should be charged for the possible lost revenue for holding the table. }\end{array}$ & 4.9 \\
\hline Courtesy & $\begin{array}{l}\text { This policy ensures that people will be charged if they are not respectful of } \\
\text { their reservation and do not cancel far enough in advance. This policy limits } \\
\text { customers from booking multiple reservations with the intent of ignoring } \\
\text { less desirable ones. }\end{array}$ & 9.2 \\
\hline Depends & $\begin{array}{l}\text { The fairness of this policy depends on variables such as the size of the party, the } \\
\text { opportunity cost of a no-show, and the forecasted demand for a particular night. }\end{array}$ & 5.6 \\
\hline Fair & $\begin{array}{l}\text { This policy is fair, both to the restaurant and to other customers who want to } \\
\text { book reservations. }\end{array}$ & 21.9 \\
\hline NA & - & 5.3 \\
\hline No control & $\begin{array}{l}\text { This policy is unfair because sometimes reservations cannot be met for reasons } \\
\text { beyond the control of the customer. Therefore, they should not be charged } \\
\text { for missing a reservation. }\end{array}$ & 8.7 \\
\hline Unfair & This policy is unfair. & 13.8 \\
\hline
\end{tabular}


Table 2. Short show categories.

\begin{tabular}{|c|c|c|}
\hline Category & Description & Percentage \\
\hline Can call & $\begin{array}{l}\text { Customers can call to let the restaurant know that they will have a } \\
\text { smaller party. }\end{array}$ & 3.0 \\
\hline $\begin{array}{l}\text { Depends } \\
\text { on size }\end{array}$ & This policy should depend on how many people did not show up. & 10.1 \\
\hline Inhospitable & $\begin{array}{l}\text { This policy is inhospitable to the guest. The restaurant should be willing } \\
\text { to accommodate all guests. }\end{array}$ & 4.8 \\
\hline Internal & $\begin{array}{l}\text { The restaurant should have a variety of seating options to deal with this } \\
\text { problem if necessary. }\end{array}$ & 5.3 \\
\hline NA & - & 2.5 \\
\hline No control & $\begin{array}{l}\text { The guests who are at the restaurant have no control over those who } \\
\text { do not show up. Therefore, they should not be penalised. }\end{array}$ & 28.8 \\
\hline Still profiting & The restaurant is still profiting from the guests who show up. & 11.7 \\
\hline Understandable & This policy is understandable in the restaurant industry. & 18.9 \\
\hline Unfair & This policy is unfair to the guest. & 14.8 \\
\hline
\end{tabular}


Table 3. Entire party seating categories.

\begin{tabular}{|c|c|c|}
\hline Category & Description & Percentage \\
\hline Inhospitable & $\begin{array}{l}\text { This policy is inhospitable to a waiting customer. The restaurant } \\
\text { should accommodate the guest as soon as they can. }\end{array}$ & 19.9 \\
\hline Internal & $\begin{array}{l}\text { This policy is reasonable because it is easier for the restaurant to serve } \\
\text { the entire table at one time. }\end{array}$ & 11.5 \\
\hline Location & $\begin{array}{l}\text { Most restaurants do not have adequate or comfortable waiting areas } \\
\text { for the guests, which diminishes the quality of the dining experience. } \\
\text { Therefore, the guest should be allowed to wait at the table to wait } \\
\text { for the others. }\end{array}$ & 5.6 \\
\hline My table & $\begin{array}{l}\text { If the customer has reserved the table for a specified time, then the } \\
\text { customer has the right to sit at the table as soon as their reservation begins. }\end{array}$ & 3.9 \\
\hline NA & - & 2.9 \\
\hline No control & $\begin{array}{l}\text { I don't have control over when other people in my party show up and } \\
\text { I should not be penalised for this. }\end{array}$ & 12.9 \\
\hline Still spending & $\begin{array}{l}\text { The restaurant will generate more revenue if they seat a partial party } \\
\text { and allow them to begin to order drinks and appetizers. }\end{array}$ & 14.0 \\
\hline Understandable & $\begin{array}{l}\text { This policy is mostly understandable. This is especially true in small } \\
\text { restaurants and restaurants that don't take reservations. }\end{array}$ & 29.3 \\
\hline
\end{tabular}


Table 4. Table holding categories.

\begin{tabular}{llc}
\hline Category & Description & Percentage \\
\hline Can call & $\begin{array}{l}\text { The customers should call if they are going to be late for a reservation. } \\
\text { The restaurant should be flexible with late customers if they call when } \\
\text { they are running late. }\end{array}$ & 55.4 \\
Fair & $\begin{array}{l}\text { This policy is fair. A reservation must have a reasonable and enforceable } \\
\text { time frame. }\end{array}$ & 28.7 \\
Longer & $\begin{array}{l}\text { This policy is unfair only because the time limit is too short. } \\
\text { Move on }\end{array}$ & $\begin{array}{l}\text { The restaurant has the right to move on to the next party if the customer } \\
\text { is unreasonably late. }\end{array}$ \\
NA & $\quad-\quad \begin{array}{l}\text { The customers should be punctual to their reservation out of courtesy for } \\
\text { the restaurant and other waiting guests. }\end{array}$ \\
Prompt & $\begin{array}{l}\text { This policy is fair if the restaurant does not make the customers wait when } \\
\text { they show up to the reservation on time. }\end{array}$ & 1.7 \\
Quid pro quo & & 0.3 \\
\hline
\end{tabular}


Table 5. Maximum duration categories.

\begin{tabular}{|c|c|c|}
\hline Category & Description & Percentage \\
\hline All night & I should be able to stay at my table for as long as I want. & 4.5 \\
\hline Business & $\begin{array}{l}\text { This policy is understandable because a restaurant is in business and needs } \\
\text { to be able to turn tables to make money. }\end{array}$ & 19.3 \\
\hline Inhospitable & A maximum duration policy is very inhospitable and unwelcoming. & 33.8 \\
\hline Internal & $\begin{array}{l}\text { The restaurant should be able to time their actions (such as ordering and } \\
\text { reservation blocking) accordingly to eliminate the need for a maximum } \\
\text { dining time. }\end{array}$ & 2.0 \\
\hline Length & $\begin{array}{l}\text { This policy is understandable as long as the time limit is generous and } \\
\text { reasonable. }\end{array}$ & 10.1 \\
\hline NA & - & 5.6 \\
\hline Others & $\begin{array}{l}\text { If there are customers waiting to dine, it is only fair to have a policy that } \\
\text { restricts the dining time of the customers before them. }\end{array}$ & 6.7 \\
\hline Rush & The restaurant should never rush the customer through the dining experience & 8.3 \\
\hline Still spending & If the customer is still spending money, they should not be subject to a time limit. & 7.8 \\
\hline Upfront & $\begin{array}{l}\text { A maximum duration policy should clearly be stated upfront for the customer, } \\
\text { such as when the reservation is made. }\end{array}$ & 2.0 \\
\hline
\end{tabular}


Table 6. Policy summary.

\begin{tabular}{lcccc}
\hline Policy & Familiarity & Understandability & Acceptability & Fairness \\
\hline Credit card guarantee & $=$ & + & $=$ & + \\
Short-show & - & - & - & $=$ \\
Table-holding & + & + & + & + \\
Entire party seating & $=$ & $=$ & $=$ & $=$ \\
Maximum duration & - & $=$ & - & $=$ \\
\hline
\end{tabular}

$\star^{\prime}={ }^{\prime}=3.5-4.5 ;^{\prime}{ }^{\prime}=2.5-3.5 ;^{\prime}++^{\prime}=4.5-5.5$. 
Figure 1. Familiarity with reservations policies.

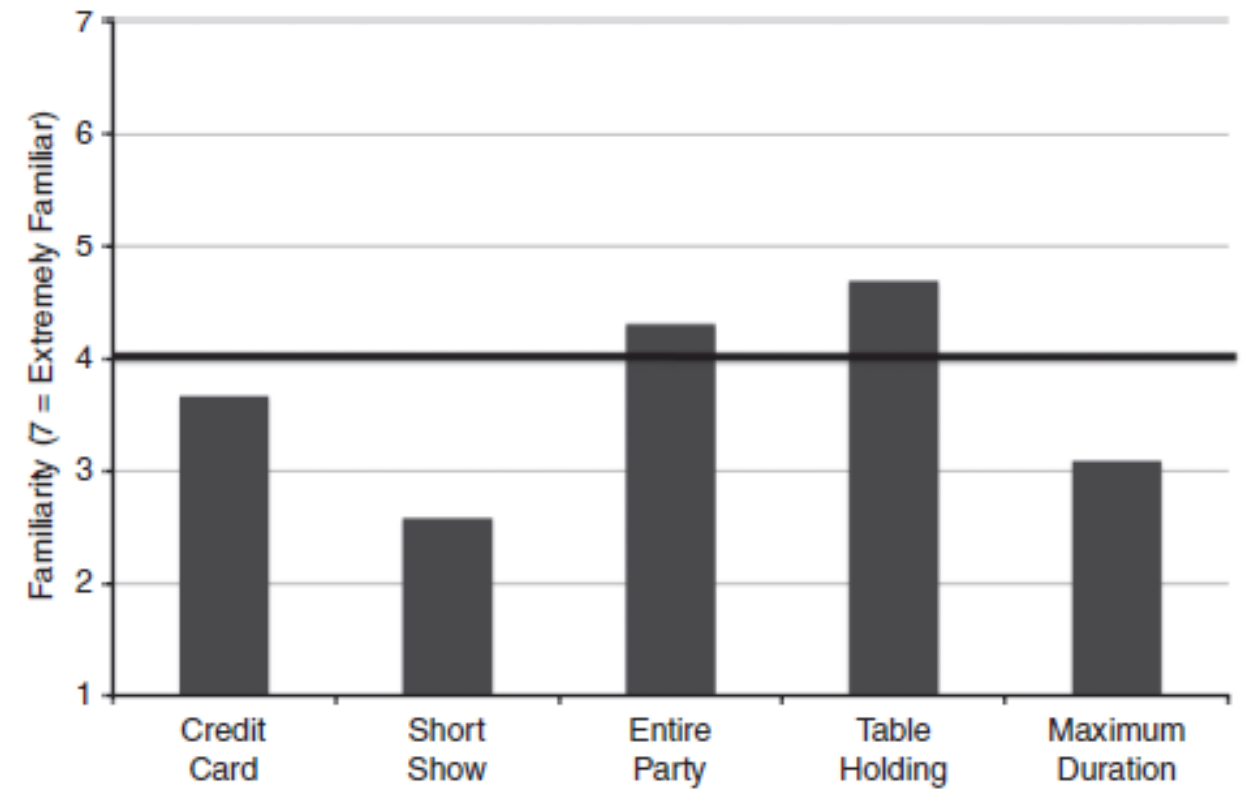


Figure 2. Acceptability of reservations policies.

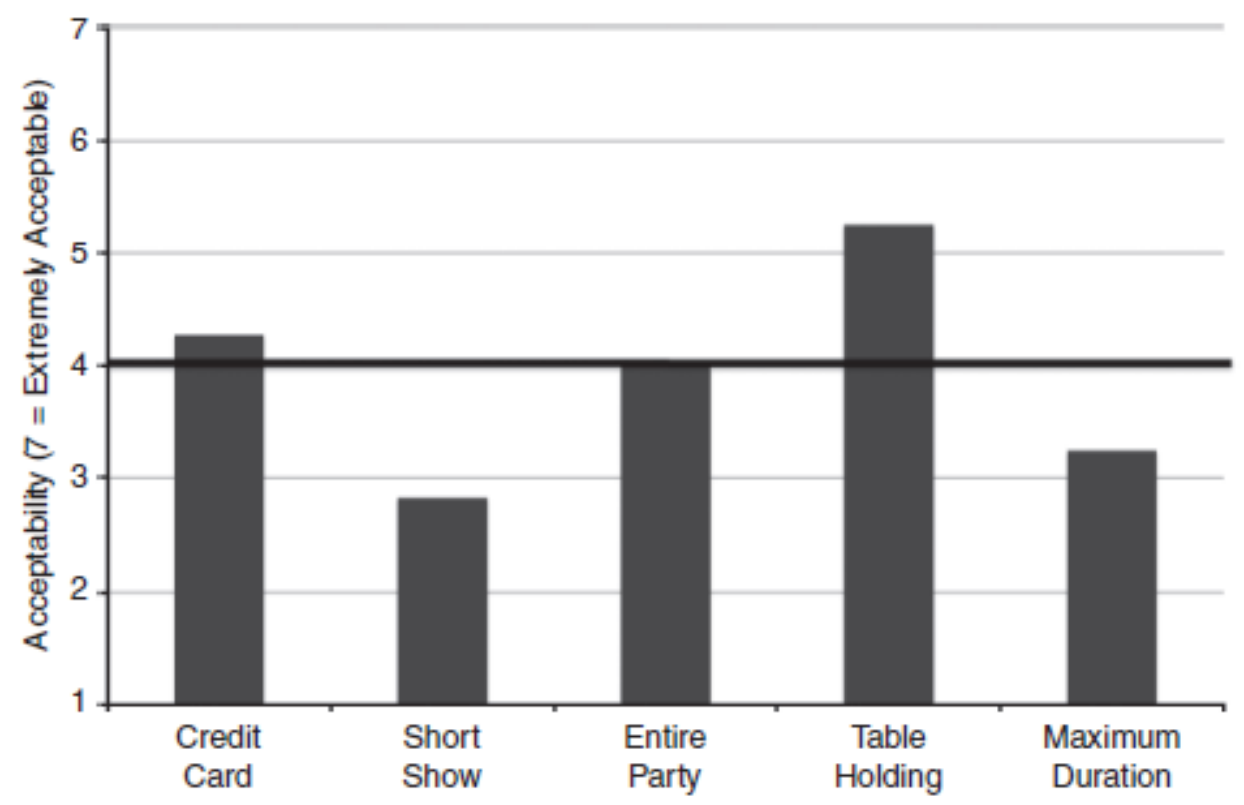


Figure 3. Understandability of reservations policies.

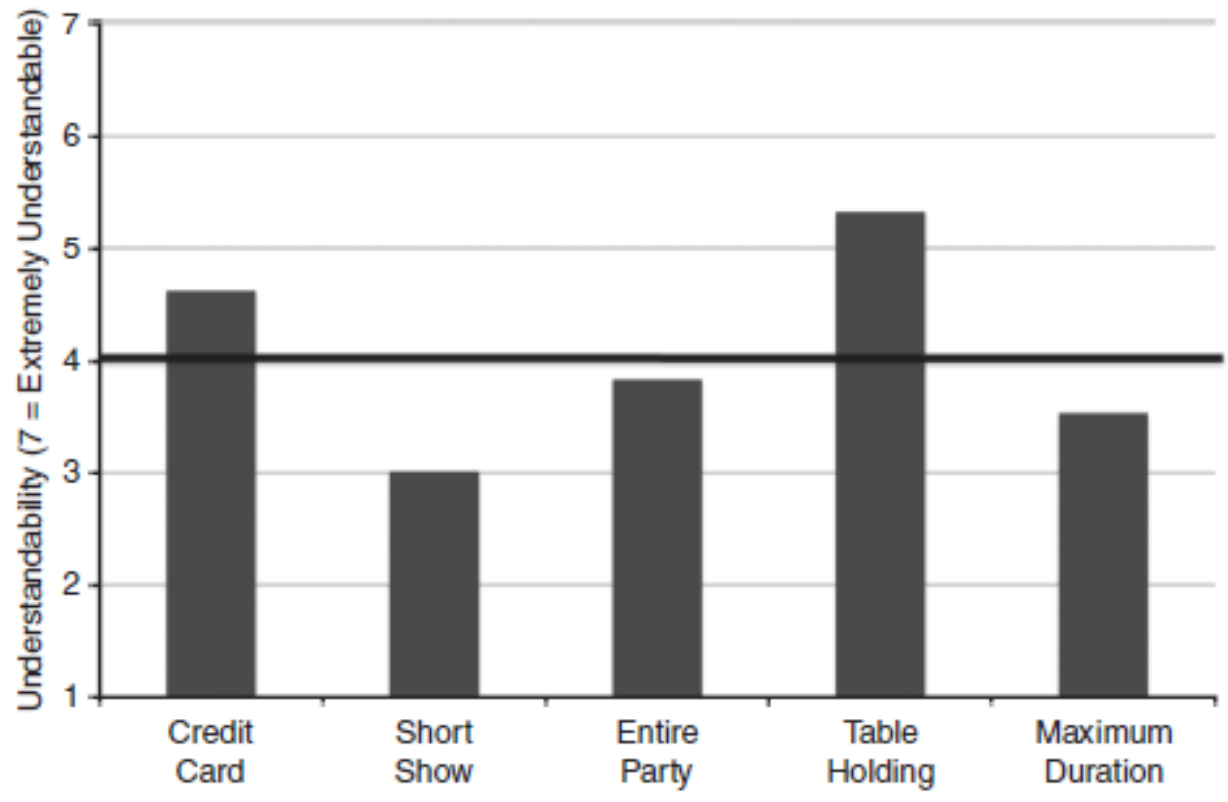


Figure 4. Unfairness of reservations policies.

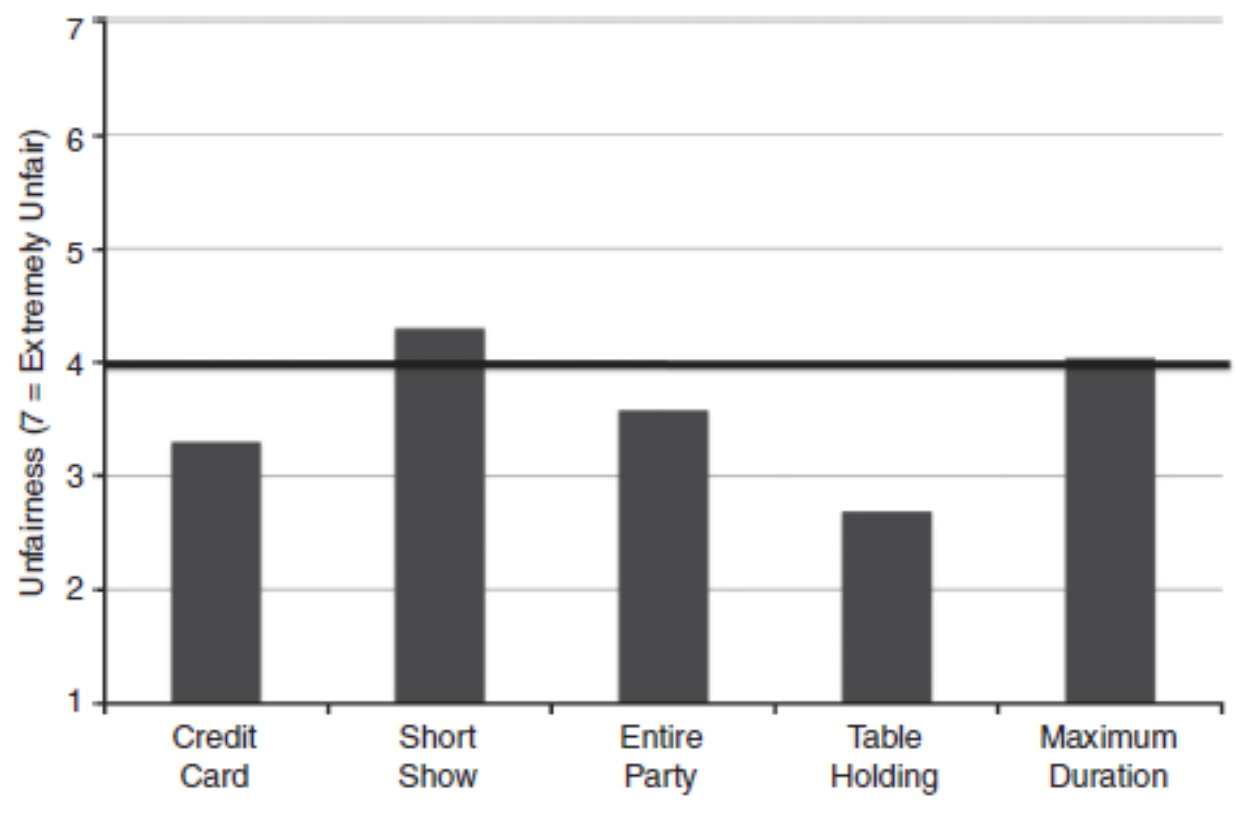




\section{References}

Averill, J. R. (1973) Personal control over aversive stimuli and its relationship to stress. Psychological Bulletin 80 (4): 286-303.

Bauer, M. (2006) No-shows, restaurant roulette and other no-nos. San Francisco Chronicle , 25 May, http://www.sfgate.com/cgi-bin/blogs/sfgate/category?blogid=26\&cat=627.

Berry, L. L., Seiders, K. and Grewal, D. (2002) Understanding service convenience. Journal of Marketing 66 (3): 1-17.

Bertsimas, D. and Shioda, R. (2003) Restaurant revenue management. Operations Research 51 (3): 472-486.

Bolton, L. E., Warlop, L. and Alba, J. W. (2003) Consumer perceptions of price (un)fairness. Journal of Consumer Research 29 (4): 474-492.

Bruni, F. (2006) Dining by stopwatch. New York Times, http://dinersjournal.blogs.nytimes.com/tag/reservations, 11 October 2006.

Campbell, M. C. (1999a) 'Why did you do that?' The important role of inferred motive in perceptions of price fairness. Journal of Product and Brand Management 8 (2): 145-152.

Campbell, M. C. (1999b) Perceptions of price unfairness: Antecedents and consequences. Journal of Marketing Research 36 (2): 187-199.

Davis, M. M. and Heineke, J. (1998) How disconfirmation, perception and actual waiting times impact customer satisfaction. International Journal of Service Industry Management 9 (1): 64-73.

Dube-Rioux, L., Schmitt, B. H. and Leclerc, F. (1988) Consumer's reactions to waiting: When delays affect the perception of service quality. In: T. Srull (ed.) Advances in Consumer Research , Vol. 16 , Provo, Ut: Association for Consumer Research, pp. 59-63.

Fischer, J. W. (2005) At Your Service . Hoboken, NJ: John Wiley \& Sons.

Hui, M. K. and Bateson, J. E. G. (1991) Perceived control and the effects of crowding and consumer choice on the service experience. Journal of Consumer Research 18 (September): 174-184.

Hui, M. K. and Tse, D. K. (1996) What to tell consumers in waits of different lengths: An integrative model of service evaluation. Journal of Marketing 60 (April): 81-90.

Kahneman, D., Knetsch, J. L. and Thaler, R. H. (1986) Fairness as a constraint on profit seeking: Entitlements in the market. The American Economic Review 76 (4): 728-741. 
Katz, K. L., Larson, B. M. and Larson, R. C. (1991) Prescription for the waiting-in-line blues: Entertain, enlighten, and engage. Sloan Management Review 32 (Winter): 44-53.

Kimes, S. E. (1994) Perceived fairness of yield management. Cornell Hotel and Restaurant Administration Quarterly 29 (1): 22-29.

Kimes, S. E. (2008) A consumer's view of restaurant reservations policies. Cornell University Center for Hospitality Research Report.

Kimes, S. E. and Chase, R. B. (1998) The strategic levers of yield management. Journal of Service Research 1 (2): 156-166.

Kimes, S. E. and Noone, B. M. (2002) Perceived fairness of yield management: An update. Cornell Hotel and Restaurant Administration Quarterly 43 (1): 28-29.

Kimes, S. E. and Wirtz, J. (2003) Has revenue management become acceptable? Findings from an international study on the perceived fairness of rate fences. Journal of Service Research 6 (2): 35-125.

Kimes, S. E. and Wirtz, J. (2007) Customer satisfaction with restaurant seating policies in casual-dining restaurants. Cornell University Center for Hospitality Research Report.

Kimes, S. E., Chase, R. B., Choi, S., Ngonzi, E. N. and Lee, P. Y. (1998) Restaurant revenue management. Cornell Hotel and Restaurant Administration Quarterly 40 (3): 40-45.

Langer, E. J. (1983) The Psychology of Control . Beverly Hills, CA: Sage.

Langer, E. J. and Rodin, J. (1976) The effects of choice and enhanced personal responsibility for the aged: A field experiment in an institutional setting. Journal of Personality and Social Psychology 34 (2): 191-198.

Langer, E. J. and Saegert, S. (1977) Crowding and cognitive control. Journal of Personality and Social Psychology 35 (2): 175-182.

Noone, B. M. and Kimes, S. E. (2005) Dining duration and customer satisfaction. Cornell University, Center for Hospitality Research Report.

Noone, B. M., Kimes, S. E., Mattila, A. and Wirtz, J. (2007) The effect of meal pace on customer satisfaction. Cornell Hotel and Restaurant Administration Quarterly 48 (3): 231-245.

Pruyn, A. and Smidts, A. (1998) Effects of waiting on the satisfaction with service: Beyond objective time measures. International Journal of Research in Marketing 15 : 321-334.

Taylor, S. (1994) Waiting for service: The relationship between delays and evaluations of service. Journal of Marketing $\mathbf{5 8}$ (April): 56-69. 
Thaler, R. F. (1985) Mental accounting and consumer choice. Marketing Science 4 (3): 199-214.

Thompson., G. M. and Kwortnik, R. J. (2008) Pooling restaurant reservations to increase service efficiency. Journal of Service Research 10 (4): 335-346.

Tom, G. and Lucey, G. (1997) A field study investigating the effect of waiting time on customer satisfaction. Journal of Psychology 131 (6): 655-660.

Urbany, J. E., Madden, T. J. and Dickson, P. R. (1989) All's not fair in pricing: An initial look at the dual entitlement principle. Marketing Letters 1 (1): 17-25.

Wirtz, J. and Kimes, S. E. (2007) The moderating effects of familiarity on the perceived fairness of revenue management pricing. Journal of Service Research 9 (3): 229-240.

Xia, L., Monroe, K. B. and Cox, J. L. (2004) The price is unfair! a conceptual framework of price fairness perceptions. Journal of Marketing 68 (October): 1-15. 